\title{
The 14 $\alpha$-Demethylase (CYP51A1) Gene is Overexpressed in Venturia inaequalis Strains Resistant to Myclobutanil
}

\author{
Guido Schnabel and Alan L. Jones
}

Department of Botany and Plant Pathology, Michigan State University, East Lansing 48824.

Current address of G. Schnabel: Department of Plant Pathology and Physiology, Clemson University, Clemson, SC 29634.

Accepted for publication 18 September 2000.

\begin{abstract}
Schnabel, G., and Jones, A. L. 2001. The 14 $\alpha$-demethylase (CYP51A1) gene is overexpressed in Venturia inaequalis strains resistant to myclobutanil. Phytopathology 91:102-110.

We identified the cytochrome P450 sterol $14 \alpha$-demethylase (CYP51A1) gene from Venturia inaequalis and optional insertions located upstream from CYP51A1 and evaluated their potential role in conferring resistance to the sterol demethylation-inhibitor (DMI) fungicide myclobutanil. The CYP51A1 gene was completely sequenced from one myclobutanil sensitive (S) and two myclobutanil-resistant (R) strains. No nucleotide variation was found when the three sequences were aligned. Allele-specific polymerase chain reaction (PCR) analysis indicated that a previously described single base pair mutation that correlated with resistance to DMI fungicides in strains of other filamentous fungi was absent in $19 \mathrm{~S}$ and $32 \mathrm{R}$ strains of $V$. inaequalis from Michigan and elsewhere. The sequencing results and PCR analyses suggest that resistance in these

strains was not due to a mutation in the sterol demethylase target site for DMI fungicides. Expression of CYP51A1 was determined for strains from an orchard that had never been sprayed with DMI fungicides (baseline orchard), and the data provided a reference for evaluating the expression of strains collected from a research orchard and from three commercial Michigan apple orchards with a long history of DMI use and a high frequency of R strains. Overexpression of CYP51A1 was significantly higher in 9 of $11 \mathrm{R}$ strains from the research orchard than in $\mathrm{S}$ strains from the baseline orchard. The high expression was correlated with the presence of a 553-bp insertion located upstream of CYP51A1. Overexpression of the CYP51A1 gene was also detected in eight of eight, five of nine, and nine of nine $\mathrm{R}$ strains from three commercial orchards, but the insertion was not detected in the majority of these strains. The results suggest that overexpression of the target-site CYP51A1 gene is an important mechanism of resistance in some field resistant strains of $V$. inaequalis, but other mechanisms of resistance also appear to exist.
\end{abstract}

Sterol demethylation inhibitors (DMI's) are broad-spectrum fungicides that are active against yeast, scab, mildew, and rust fungi. They are systemic compounds with highly protective and curative activity at low doses but also have selective action against nontarget organisms $(7,23)$. However, because of their site-specific mode of action, the intensive use of DMI's has led to the development of resistance in a number of fungi of medical $(16,18,44)$ and agricultural importance $(14,37,41)$. Currently, in an effort to develop new drugs and antiresistance strategies, the molecular basis for DMI fungicide resistance in Candida albicans, an important opportunistic pathogen of humans, is being intensively studied. Fluconazole resistance in clinical isolates of $C$. albicans has been associated with a combination of several distinct mechanisms $(12,39,44)$. The most common mechanisms include mutations in the target enzyme of azoles, a cytochrome P450 catalyzing the $14 \alpha$-demethylation of lanosterol $(29,38,43)$. The gene encoding $14 \alpha$-demethylase has been named $P-450_{14 d m}, E r g 11$, and CYP51A1; the last designation will be used here as recommended by Nelson et al. (26). Energy-dependent drug efflux mechanisms have also been implicated in the acquired resistance of Candida spp. to azole antifungal agents $(1,6,12,30,39,44)$. Phytopathologists have recently demonstrated that both mechanisms can confer resistance to DMI fungicides in filamentous fungi. Mutations within the $14 \alpha$-demethylase gene confer DMI resistance in laboratory mutants of Ustilago maydis and Penicillium italicum and in field strains of Uncinula necator and Erysiphe graminis $(6,9,11,19)$. High expression of two Aspergillus nidulans genes (AtrA and AtrB) and a Penicillium digitatum gene (PMRI), which

Corresponding author: A. L. Jones; E-mail address: jonesa@pilot.msu.edu

Publication no. P-2000-1016-01R

(c) 2001 The American Phytopathological Society encode drug efflux proteins of the ATP-binding cassette $(\mathrm{ABC})$ transporter family, has been associated with DMI resistance $(8,25)$. Other mechanisms include a defect in $\Delta 5,6$ desaturation or high levels of $14 \alpha$-demethylase caused by the overexpression of the CYP51Al gene $(15,42)$. As yet, very few of these mechanisms of resistance have been characterized in resistant field strains of plant pathogens.

Field resistance to DMI fungicides in Venturia inaequalis arose in the mid-1980s and has increased significantly in Michigan and worldwide $(4,21,24,33,35)$. This development of DMI-resistant field strains poses a real threat, because the selection of fungal strains with normal virulence and a relatively high degree of resistance can cause failure in disease control. To the best of our knowledge, no reports have been published on the molecular basis of DMI fungicide resistance in $V$. inaequalis. Such information could lead to improved spray recommendations for apple growers, quick methods for detecting DMI fungicide resistance in field populations, and improved design of antifungal compounds.

We identified and sequenced the complete $14 \alpha$-demethylase gene (CYP51Al) from $V$. inaequalis, encoding the target enzyme of DMI fungicides, as well as optional insertions located upstream from the gene and evaluated their potential for conferring resistance to DMI fungicides in $V$. inaequalis field strains.

\section{MATERIALS AND METHODS}

Strains of $V$. inaequalis, DNA isolation, and sensitivity to myclobutanil. The source of most $V$. inaequalis strains used in this study are listed in Table 1. Additional strains of V. inaequalis were isolated in 1997 from the Entomology Farm (Ent strains) and in 1999 from the Botany Farm (BF strains). Both farms are research orchards located in East Lansing, MI. Strains from commercial orchards in Michigan (ER, JM, and HM) were isolated in 
1999. The Botany Farm and orchards ER, JM, and HM had been exposed to at least four DMI sprays per year since the introduction of DMI fungicides in the early to mid-1980s, and all isolates were from lesions collected from trees treated with myclobutanil. The Entomology Farm orchard had never been sprayed with DMI fungicides. It was located $0.1 \mathrm{~km}$ east of the Botany Farm orchard.

Genomic DNA was isolated from strains of $V$. inaequalis as described previously (31). Nuclear DNA (nDNA) was purified and concentrated by centrifugation of genomic DNA in a $\mathrm{CsCl}$ density gradient containing the fluorescent dye bisbenzimide (13).

The reaction of each strain to myclobutanil was determined in mycelium growth assays on potato dextrose agar amended with myclobutanil at 0 and $0.3 \mu \mathrm{g} / \mathrm{ml}$. Relative growth (RG) values were determined with at least two replicates per isolate. The RG value was defined as the diameter of a mycelial colony on media amended with $0.3 \mu \mathrm{g} / \mathrm{ml}$ of myclobutanil per colony diameter on unamended media $\times 100$. Colony diameters were measured after 4 weeks of colony growth at $20^{\circ} \mathrm{C}$. A strain was classified as sensitive (S) to myclobutanil if its RG was 30 or less or as resis- tant (R) to myclobutanil if its RG was 70 or higher. Isolates with $R G$ values between 31 and 69 were intermediate isolates and were not included in this study.

Creating polymerase chain reaction libraries of $V$. inaequalis DNA. Total DNA was digested separately with restriction enzymes DraI, SacI, and SspI. Subsequently, an adaptor (5'CTAATACGACTCACTATAGGGCTCGAGCGGCCGCCCGGG

CAGGT-3') and (5'-P-ACCTGCCC-NH $\left.{ }_{2}-3^{\prime}\right)$ was ligated onto the ends of the digested DNA fragments (32). The resulting DraI, $S a c \mathrm{I}$, and $S s p \mathrm{I}$ polymerase chain reaction (PCR) libraries were stored at $-20^{\circ} \mathrm{C}$.

PCR amplification of CYP51A1 and its upstream flanking sequence. Internal fragments of CYP51A1 were amplified with primer pairs AJ235 (5'-GARCCACCWGTTGTMTTTCA-3') and AJ236 (5'-GTASTYYTCTTCGGCGTTGAC-3'), AJ240 (5'-TTCACTGGTTTCCCTTCTTC-3') and AJ241 (5'-KWKATTAKKGKKACATAGGA-3') and AJ291 (5'-GTCTCACCACCGAAGCTCTCA-3') and AJ313 (5'-GCRAAYTKCTCDCCRATRCABCGAT-3') (Fig. 1). Reaction mixtures $(50 \mu \mathrm{l})$ contained $1 \mu \mathrm{l}$

TABLE 1. Reaction of field strains of Venturia inaequalis from different geographical regions to myclobutanil and allele specific amplification-polymerase chain reaction (ASA-PCR) analysis of CYP51A1 DNA

\begin{tabular}{|c|c|c|c|c|}
\hline \multirow[b]{2}{*}{ Origin (reference) } & \multicolumn{2}{|c|}{ Amplification success with primer pair ${ }^{\mathrm{a}}$} & \multirow[b]{2}{*}{ Strains } & \multirow[b]{2}{*}{ Reaction $^{\mathrm{b}}$} \\
\hline & AJ250-F, AJ244-R & AJ251-F, AJ244-R & & \\
\hline Michigan (this study) & + & 0 & $\begin{array}{l}\text { Ent3, Ent4, Ent7, Ent15, Ent23, Ent24, Ent25, Ent26, Ent27, Ent28, Ent31, } \\
\text { Ent50, Ent52, Ent56 }\end{array}$ & S \\
\hline France (17) & + & 0 & TUM2, UZ4 & $\mathrm{S}$ \\
\hline $\begin{array}{l}\text { Michigan (32; } \\
\text { this study) }\end{array}$ & + & 0 & $\begin{array}{l}\text { F335, F336, F349, F411, F445, F446, F853, MSU33, MSU40, MSU37, } \\
\text { MSU18, Ent2, Ent21, Ent38, Ent45, Ent54, BF1, BF5, BF6, BF8, BF18, } \\
\text { BF19, BF20, BF26, BF29, BF35 }\end{array}$ & $\mathrm{R}$ \\
\hline Germany (34) & + & 0 & B1, B9 & $\mathrm{R}$ \\
\hline
\end{tabular}

${ }^{a}$ Two rounds of PCR were performed for each strain. First, a 404-bp fragment spanning codon 133 was PCR amplified from total DNA with primers AJ243 and AJ244. Then, using a 100-fold dilution of the first round product as template, wild-type primer AJ250 and mutant primer AJ251 were used with AJ244 to selectively amplify CYP51A1 genes with nucleotides TAT and TTT at codon 133, respectively.

${ }^{\mathrm{b}}$ Sensitivity to $0.3 \mu \mathrm{g} / \mathrm{ml}$ of myclobutanil was determined in mycelium growth assays on potato dextrose agar. A strain was considered sensitive (S) to the fungicide if the relative growth (RG) was 30 or less and resistant (R) if RG was 70 or higher.

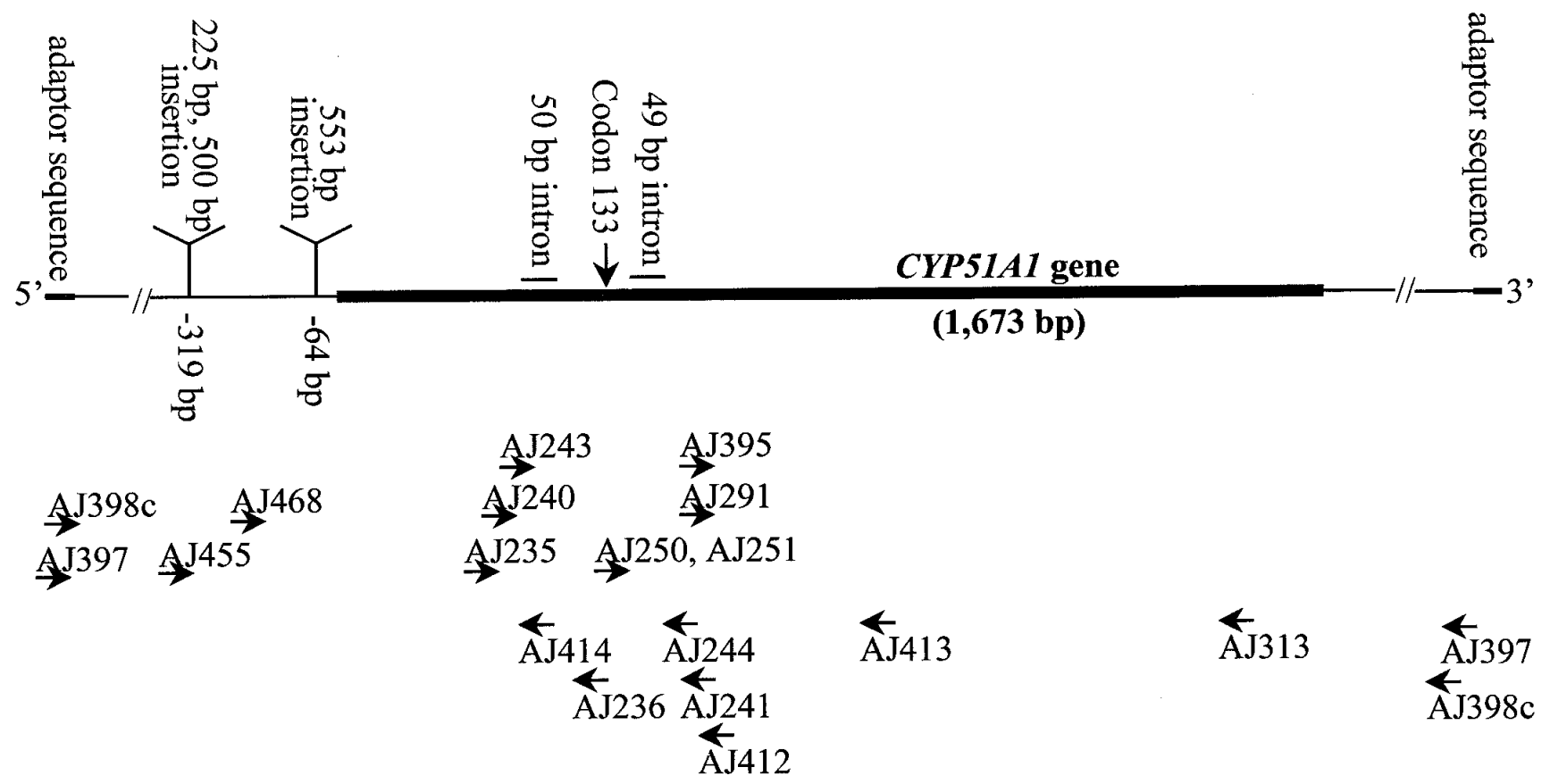

Fig. 1. Location for three insertions found upstream from the $5^{\prime}$ end of the CYP51A1 gene. Screening for the 55-bp insertion was performed by polymerase chain reaction (PCR) with primers AJ468 and AJ414 using total DNA. Also shown are the locations of primers used to amplify CYP51A1 fragments and its 5 and 3' flanking sequences. Genomic DNA was digested with restriction enzymes SacI or Dra1 and an oligonucleotide adapter sequence was ligated to the ends of the digestion products. Allele-specific primers AJ397 and AJ398c were used to PCR amplify the 5' and 3' ends of CYP51A1. 
ATGGGACTCCTCTCTCCTTTGCTCGCCTNGTTACCGGGCAGCGACCGCAGTTGGTTATTTTACACTCTTGCCTCCTTCGG 80 $\begin{array}{lllllllllllllllllllllllllllllll}M & G & \text { L } & \text { L } & \text { S } & \text { P } & \text { L } & \text { L } & \text { A } & \text { X } & \text { L } & \text { P } & \text { G } & \text { S } & \text { D } & \text { R } & \text { S } & \text { W } & \text { L } & \text { F } & \text { Y } & \text { T } & \text { L } & \text { A } & \text { S } & \text { F } & \text { G } & 27\end{array}$

CTTCACCGTTGCAATCGTCGCCGCCAACCTTGTCAAGCAACTCTTATTCTCAAACCCAAACGAACCTCCAGTAGTCTTCC 160

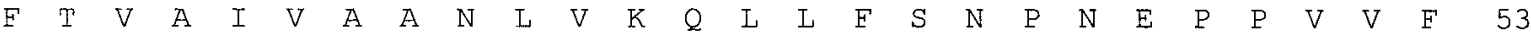

ACTGGTTTCCCTTCTTCGGCAACACGGTCGTCTACGGCATCGATCCTATCAAGTTTTTCGCCGAGTGCAAGGAAAAGgta 240 $\begin{array}{lllllllllllllllllllllllllllll}H & W & F & P & F & F & G & N & T & V & V & Y & G & I & D & P & I & K & E & F & A & E & C & K & E & K & & 79\end{array}$ CR1

atgcgacaatgagaatgcaagttgcgtggagctaacttgtctccCagCATGGCGATATCTTTACCTTCATTCTTCTTGGC 320 $\begin{array}{llllllllllllllllllllll}H & G & D & I & F & T & F & I & L & I & G & 90\end{array}$

AGGAAAACAACAGTCTACATTGGTACAAAGGGAAACGAATTCATTCTCAATGGCAAACAGAGCCATGTCAACGCAGAGGA 400 $\begin{array}{llllllllllllllllllllllllllll}R & K & T & T & V & Y & I & G & T & K & G & N & E & F & I & I & N & G & K & Q & S & H & V & N & A & E & E & 117\end{array}$ CR2

AATCTATAGCCCCCTGACGACGCCCGTCTTCGGCTCCGATGTTGTCTATGATTGCCCAAACTCGAAATTGATGGAGCAAA 480 $\begin{array}{lllllllllllllllllllllllllllll}I & Y & S & P & L & T & T & P & V & F & G & S & D & V & V & Y & D & C & P & N & S & K & L & M & E & Q & 143\end{array}$ AGAAGgtatgctgccaccattctttcgcaagagactcctgctgatatccacaagTTCGTCAAGTACGGTCTCACCACCGA 560 $\begin{array}{llllllllllll}K & K & F & V & K & G & L & T & T & 154\end{array}$

AGCTCTCAAATCCTATGTCACCCTCATCCAACAAGAAGTCGAAGACTATACCAAACGCTACCCTCAATTCAAAGGCGAAA 640 $\begin{array}{llllllllllllllllllllllllllllll}A & L & K & S & Y & V & T & I & I & Q & Q & E & V & E & D & Y & T & K & R & Y & P & Q & F & K & G & E & 180\end{array}$ AGGGCAGCTTCGATGTTTGCGCTTCCATGGCCGAAATCACAATCTTCACTGCTTCCCGCTCACTACAAGGCAAGGAGGTT 720 $\begin{array}{lllllllllllllllllllllllllllll}K & G & S & F & D & V & C & A & S & M & A & E & I & T & I & F & T & A & S & R & S & L & \& & G & K & E & V & 207\end{array}$ CR3

CGCGACAAGTTTGACGCCAGCTTTGCAGACCTCTTCCACGATTTGGATATGGGCTTCTCTCCTATCAACTTCATGCTTCC 800 $\begin{array}{lllllllllllllllllllllllllllllll}R & D & K & F & D & A & S & E & A & D & L & F & H & D & L & D & M & G & F & S & P & I & N & E & M & L & P & 234\end{array}$

CTGGGCCCCTCTTCCACACAATCGTCGCCGAGATGCCGCGAACAAAAAGATGACGGAGACATATTTGGAAATTATCCAAT 880

$\begin{array}{llllllllllllllllllllllllllll}W & A & P & L & P & H & N & R & R & R & D & A & A & N & K & K & M & T & E & T & Y & L & E & I & I & Q & 260\end{array}$

CGAGAAAAGCAGAGGGCGTCAAAAAGGATTCAGAGGACATGATTTGGAATTTGATGCAGTGTGTATACAAGAATGGCACT 960 $\begin{array}{lllllllllllllllllllllllllllll}S & R & K & A & E & G & V & K & K & D & S & E & D & M & I & W & N & L & M & Q & C & V & Y & K & N & G & T & 287\end{array}$ CR 4

CCCATCCCGGACAAAGAAATCGCCCACATGATGATCGCGCTGCTCATGGCCGGCCAGCACTCGTCCTCTAGCACCTCGTC 1040 $\begin{array}{llllllllllllllllllllllllllll}P & I & \mathrm{P} & \mathrm{D} & \mathrm{K} & \mathrm{E} & \mathrm{I} & \mathrm{A} & \mathrm{H} & \mathrm{M} & \mathrm{M} & \mathrm{I} & \mathrm{A} & \mathrm{L} & \mathrm{L} & \mathrm{M} & \mathrm{A} & \mathrm{G} & \mathrm{Q} & \mathrm{H} & \mathrm{S} & \mathrm{S} & \mathrm{S} & \mathrm{S} & \mathrm{T} & \mathrm{S} & \mathrm{S} & 314\end{array}$

CTGGATTCTACTTCGACTAGCTACCAGACCTGATATCCAGGAAGAACTATACCAAGAACAAATTCGGGTTTGCGGCGCTG 1120

$\begin{array}{lllllllllllllllllllllllllllll}W & I & L & L & R & L & A & T & R & P & D & I & Q & E & E & L & Y & Q & E & Q & I & R & V & C & G & A & 340\end{array}$ ATCTTCCACCGTTGCAGTACGAAGATCTTGCTCGCATGCCTCTCCACAACCAGATTATCAAAGAAACTCTTCGCATGCAT 1200 $\begin{array}{lllllllllllllllllllllllllllll}\mathrm{D} & \mathrm{I} & \mathrm{P} & \mathrm{P} & \mathrm{I} & \mathrm{Q} & \mathrm{Y} & \mathrm{E} & \mathrm{D} & \mathrm{L} & \mathrm{A} & \mathrm{R} & \mathrm{M} & \mathrm{P} & \mathrm{L} & \mathrm{H} & \mathrm{N} & \mathrm{Q} & \mathrm{I} & \mathrm{I} & \mathrm{K} & \mathrm{E} & \mathrm{T} & \mathrm{L} & \mathrm{R} & \mathrm{M} & \mathrm{H} & 367\end{array}$ TCGCCAATTCACAGCATCTTGCGTGCCGTCAAACAGCCTATGCCTGTCGAAGGAACTCCTTACACCATCCCCACCTCGCA 1280 $\begin{array}{lllllllllllllllllllllllllllll}S & P & I & H & S & I & L & R & A & V & K & Q & P & M & P & V & E & G & T & P & Y & T & I & P & T & S & H & 394\end{array}$ TGTTCTCCTTGCTGCTCCCATCGCATCTGGAGGCTCGCCAATGTACTTTCCAGCTCCTGAGAAGTGGGAGCCTCACCGTT 1360 $\begin{array}{llllllllllllllllllllllllllllll}V & I & L & A & A & P & I & A & S & G & G & S & P & M & Y & F & P & A & P & E & K & W & E & P & H & R & 420\end{array}$ GGGACGAAGGATCAGGAGGAACCAACATCTCGGGCGGCGAAAACGGTGGCGAAGAGAAAGAGGATTACGGCTATGGACTC 1440 $\begin{array}{llllllllllllllllllllllllllllll}W & D & E & G & S & G & G & T & N & I & S & G & G & E & N & G & G & E & E & K & E & D & Y & G & Y & G & L & 447\end{array}$ ATCACAAAGGGCGCCAGCTCGCCGTACCTTCCGTTCGGCGCTGGAAGACATAGGTGTATCGGCGAACAATTTGCATATAT 1520 $\begin{array}{llllllllllllllllllllllllllll}I & \mathrm{I} & \mathrm{K} & \mathrm{G} & \mathrm{A} & \mathrm{S} & \mathrm{S} & \mathrm{P} & \mathrm{Y} & \mathrm{L} & \mathrm{P} & \mathrm{F} & \mathrm{G} & \mathrm{A} & \mathrm{G} & \mathrm{R} & \mathrm{H} & \mathrm{R} & \mathrm{C} & \mathrm{I} & \mathrm{G} & \mathrm{E} & \mathrm{Q} & \mathrm{F} & \mathrm{A} & \mathrm{Y} & \mathrm{M} & 474\end{array}$ GCAGTTGAACACGGTTCTCGCGACGCAAGTTCGCGAATTCAAGTTCAGTTTGAGGGAAGGAGAGTCGTTCCCCAAGACCG 1600 $\begin{array}{lllllllllllllllllllllllllll}Q & \mathrm{~L} & \mathrm{~N} & \mathrm{~T} & \mathrm{~V} & \mathrm{~L} & \mathrm{~A} & \mathrm{~T} & \mathrm{Q} & \mathrm{V} & \mathrm{R} & \mathrm{E} & \mathrm{F} & \mathrm{K} & \mathrm{F} & \mathrm{S} & \mathrm{L} & \mathrm{R} & \mathrm{E} & \mathrm{G} & \mathrm{E} & \mathrm{S} & \mathrm{F} & \mathrm{P} & \mathrm{K} & \mathrm{T} & 500\end{array}$ ACTTCTCTTCTCTATTTTCTGGACCTCTACGCCCCGCGTGGTTGAACTGGGAACGTAGAGAGAAGTCCTCATGA 1674 $\begin{array}{lllllllllllllllllllllllllllll}D & F & S & S & L & F & S & G & P & L & R & P & A & W & L & N & W & E & R & R & E & K & S & S & . & & & 525\end{array}$

Fig. 2. Nucleotide and deduced amino acid sequence of the CYP51A1 gene from Venturia inaequalis (CYP51A1). The deduced amino acid sequence is indicated by the single-letter amino acid code below the nucleotides. Exons of CYP51A1 are in upper case, introns are in lower case. The underlined amino acid sequences correspond to regions CR1 to CR6, known to be conserved among CYP51A1 genes. Sequences for the CYP51A1 genes from myclobutanil-resistant strains F445 and Ent54 and myclobutanil-sensitive strain Ent27 were identical. The possible mutation site at codon 133 (nucleotide 448 ) is indicated in bold. 
(20 to $60 \mathrm{ng}$ ) of nDNA, $1.5 \mu \mathrm{M}$ each primer, $200 \mu \mathrm{M}$ each dNTP, 1.25 units of Taq (DNA polymerase) (Gibco BRL, Gaithersburg, MD), $20 \mathrm{mM}$ Tris- $\mathrm{HCl}$ (pH 8.4), $50 \mathrm{mM} \mathrm{KCl}$, and $1.5 \mathrm{mM}$ $\mathrm{MgCl}_{2}$. Mineral oil was added to prevent evaporation. Cycling parameters were $94^{\circ} \mathrm{C}$ for 2 min followed by 30 cycles of $94^{\circ} \mathrm{C}$ for $30 \mathrm{~s}, 45^{\circ} \mathrm{C}$ for $1 \mathrm{~min}$, and $72^{\circ} \mathrm{C}$ for $1 \mathrm{~min}$. Reactions were performed in a minicycler (Model PTC-150-16, MJ Research Inc., Watertown, MA). All PCR products were analyzed by electrophoresis with $1 \%$ agarose gels in $0.5 \times$ Tris-Borate-EDTA buffer.

The $5^{\prime}$ and $3^{\prime}$ ends of $C Y P 51 A 1$ and the $1.5-\mathrm{kb}$ upstream region were amplified by a PCR method for walking in uncloned total DNA (32). Basically, nested sets of gene-specific and allelespecific primers were used to amplify the flanking sequences of CYP51A1 from the PCR libraries. The $5^{\prime}$ and $3^{\prime}$ ends of the CYP51A1 gene were successfully amplified using the SacI library and the DraI library, respectively, as a template. The gene-specific primers used to amplify the $5^{\prime}$ end of CYP51Al were AJ413 (5'AATCCTTTTTGACGCCCTCTGCTTTTCTCG-3') followed by AJ412 (5'-TTGCCTTGTAGTGAGCGGGAAGCAGTGAAGATTGTGATT-3'). The gene-specific primer used to amplify the $3^{\prime}$ end of CYP51A1 was AJ395 (5'-GTCTCTCACCACCGAAGCTCTCAAATCCTATGT-3') for both rounds of PCR. Adaptorspecific primers AJ397 (5'-GGATCCTAATACGACTCACTATAGGGC-3') and AJ398c (5'-AATAGGGCTCGAGCGGC-3') were used for the first and second rounds of PCR, respectively (Fig. 1). Reactions were performed in a total volume of $50 \mu \mathrm{l}$ containing $2.5 \mu \mathrm{l}$ (50 to $100 \mathrm{ng}$ ) of each PCR library, $0.3 \mu \mathrm{M}$ each primer, $350 \mu \mathrm{M}$ each dNTP, 2.5 units of Expand long template DNA polymerase (Roche Molecular Biochemicals, Indianapolis, IN), and 1× Expand buffer 3. Mineral oil was added to prevent evaporation. Cycling parameters were $94^{\circ} \mathrm{C}$ for $1 \mathrm{~min}$ followed by 35 cycles (first PCR) and 23 cycles (second PCR) at $94^{\circ} \mathrm{C}$ for $30 \mathrm{~s}$ and $68^{\circ} \mathrm{C}$ for $6 \mathrm{~min}$.

Upstream regions of the CYP51A1 gene were amplified with forward primers AJ455 (5'-CGACGGCGATGTTGTTTACGAGATGTA-3') and AJ468 (5'-ATCCCTGAATTTGAGAGCACT-3') and with reverse primer AJ414 (5'-CTGCCAAGAAGAATGAAGGTAAA-3') as described above for the internal CYP51A1 fragments at an annealing temperature of $50^{\circ} \mathrm{C}$.

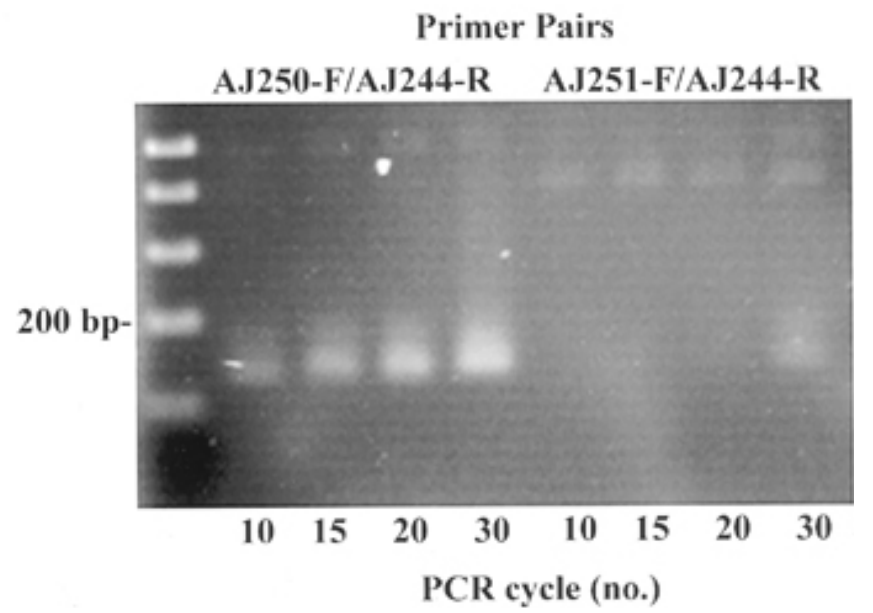

Fig. 3. The effect of the number of cycles on allele-specific amplificationpolymerase chain reaction (ASA-PCR) of CYP51A1 DNA from myclobutanil-sensitive Venturia inaequalis strain Ent50. ASA-PCR primers AJ250 (5'-CTCCGATGTTGTCTA-3') and AJ251 (5'-CTCCGATGTTGTCTT-3') were identical except for the base at the $3^{\prime}$ end (underlined). Primer AJ250 detected the complementary $\mathrm{T}$ nucleotide in the second position of codon 133 , whereas AJ251 would detect a possible mutation for demethylationinhibitor resistance at this position. ASA-PCR was performed simultaneously with both primers with the product from PCR amplification, with primers AJ243 and AJ244 as a template. Products were analyzed by agarose gel electrophoresis after 10,15, 20, and 30 PCR cycles.
PCR amplification of an actin gene fragment from $V$. inaequalis. An approximately 770-bp fragment was PCR amplified from genomic DNA by degenerate primers AJ665 (5'-AAYTGGGAYGAYATGGARAA-3') and AJ666 (5'-ATCCACATYTGYTGRAANGT-3'). The reaction mixture was identical to the reaction mixture and amplification protocol used for PCR amplifying of the initial CYP51A1 fragment.

Allele-specific amplification-PCR. Two rounds of PCR were performed for each strain. First, a 404-bp fragment spanning codon 133 was PCR amplified from total DNA with primers AJ243 (5'-GTTTCCCTTCTTCGGCAACAC-3') and AJ244 (5'TGAGAGCTTCGGTGGTGAGAC-3'). Second, with a 100-fold dilution of the first round product as template, wild-type primer AJ250 (5'-CTCCGATGTTGTCTA-3') and mutant primer AJ251 (5'-CTCCGATGTTGTCTT-3') were used with AJ244 to selectively amplify $C Y P 51 A 1$ genes with nucleotides TAT and TTT at codon 133, respectively (Fig. 1). PCR reactions and cycle parameters were identical to those used for amplifying internal fragments of CYP51A1 (described previously), except the annealing temperature for both PCR reactions was $56^{\circ} \mathrm{C}$ and the number of cycles for allele-specific amplification (ASA)-PCR was 20.

Prediction of promoter sequences. Promoter sequences were predicted with Neural Network, a method that finds eukaryotic and prokaryotic promoters in a DNA sequence (28).

DNA sequencing. PCR products were purified with a PCR DNA purification system (Wizard PCR Preps DNA Purification System, Promega, Madison, WI) and sequenced at the Plant Research Laboratory Sequencing Facility, Michigan State University, East Lansing.

Isolation of RNA. The extraction procedures described below were performed at room temperature, and the centrifugations were conducted at $4^{\circ} \mathrm{C}$ for $10 \mathrm{~min}$ at $10,000 \mathrm{rpm}$. Single spore isolates of $V$. inaequalis not older than 3 weeks were ground with a tissue grinder, transferred into $250-\mathrm{ml}$ flasks containing $50 \mathrm{ml}$ of potato dextrose broth (PDB), and incubated for 3 to 4 weeks. Cultures from some R strains were also amended with $0.3 \mu \mathrm{g} / \mathrm{ml}$ of myclobutanil (Nova 40W, Rohm and Haas Company, Philadelphia) $16 \mathrm{~h}$

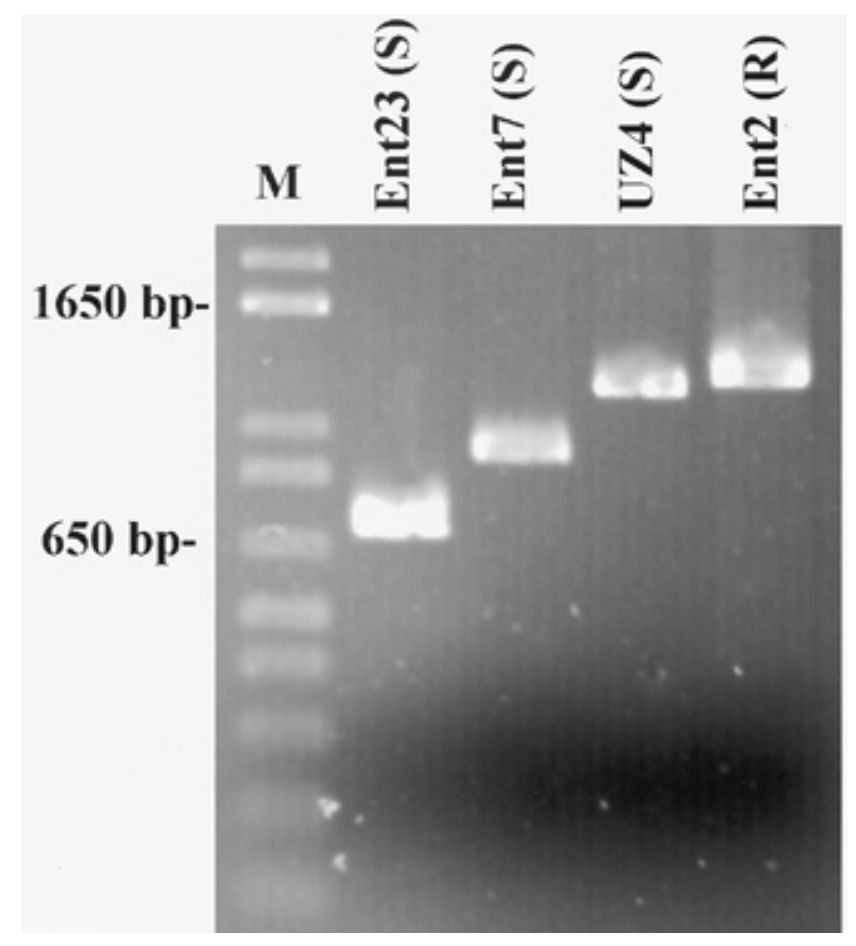

Fig. 4. Gel electrophoresis analysis of polymerase chain reaction products amplified with primers AJ455 and AJ414 from myclobutanil-sensitive (S) strains Ent23, Ent7, and UZ4 and from myclobutanil-resistant (R) strain Ent2. Lane $\mathrm{M}=1-\mathrm{kb}$ plus ladder. 
before RNA extraction. Mycelium was washed once with sterile water and dried between paper towels. Approximately $100 \mathrm{mg}$ of mycelium was pulverized in a mortar with liquid nitrogen and transferred into a mixture of $2 \mathrm{ml}$ of lysis buffer $(0.6 \mathrm{M} \mathrm{NaCl}$, $10 \mathrm{mM}$ EDTA, $100 \mathrm{mM}$ Tris-HCL (pH 8.0), and 4\% sodium dodecyl sulfate) and $2 \mathrm{ml}$ of phenol (saturated with $0.1 \mathrm{M}$ Tris$\mathrm{HCL}$ at $\mathrm{pH}$ 8.0). The mixture was shaken vigorously for at least $20 \mathrm{~min}$ and centrifuged. The upper phase was extracted with phenol, mixed with $0.75 \mathrm{vol}$ of $8 \mathrm{M} \mathrm{LiCl}$, stored at $4^{\circ} \mathrm{C}$ overnight, vortexed, and centrifuged. The pellet was resuspended in $0.3 \mathrm{ml}$ of double-distilled water and mixed with $0.03 \mathrm{ml}$ of $3 \mathrm{M}$ sodium acetate (pH 5.2) and $0.75 \mathrm{ml}$ of ethanol. The solution was stored at $-80^{\circ} \mathrm{C}$ for $30 \mathrm{~min}$. After centrifugation, the pellet was washed once with $80 \%$ ethanol and resuspended in 50 to $100 \mu \mathrm{l}$ of deionized formamide. The samples were stored at $-20^{\circ} \mathrm{C}$ until further use.

cDNA synthesis. RNA in formamide was resuspended in water, DNase treated and reverse transcribed for real-time PCR analysis. Approximately 5 to $10 \mu \mathrm{g}$ of RNA in formamide was added to $295 \mu \mathrm{l}$ of diethylpyrocarbonate water, and $0.03 \mathrm{ml}$ of $3 \mathrm{M}$ sodium acetate $(\mathrm{pH} 5.2)$ and $0.75 \mathrm{ml}$ of ethanol were added. The sample was chilled for $30 \mathrm{~min}$ at $-80^{\circ} \mathrm{C}$. The RNA was pelleted by centrifugation for $10 \mathrm{~min}$ at $13,000 \mathrm{rpm}$ and subsequently washed with $70 \%$ ethanol. The pellet was air dried and resuspended in $5 \mu \mathrm{l}$ of RNase-free water. DNase treatment was performed according to the manufacturer's protocol (RQ1 RNase-free DNase, Promega, Madison, WI). Reverse transcription was performed in a total of $20 \mu \mathrm{l}$ using SUPERSCRIPT II (Gibco BRL) with $0.13 \mu \mathrm{l}$ of 10× Hexanucleotide Mix (Boehringer $\mathrm{GmbH}$, Mannheim, Germany) following the manufacturer's recommendations.

Quantification of CYP51A1 expression using real-time PCR. Real-time PCR is a fluorescence-based method of quantifying PCR products during the exponential phase of amplification. As target DNA is amplified, fluorescence increases as a result of the binding of the dsDNA to the DNA stain SYBR Green (PerkinElmer Applied Biosystems, Foster City, CA). Reactions were performed in an ABI sequence detection system (Prism 7700, Perkin-Elmer) following the manufacturer's recommendations. The point in time during cycling at which an amplification plot intersects with an arbitrary threshold limit $\left(\mathrm{C}_{\mathrm{T}}\right)$ was detected for each sample. The comparative $\mathrm{C}_{\mathrm{T}}$ method (separate tubes) was chosen to determine CYP51Al expression relative to the expression of the sample with the least copies of CYP51A1 mRNA using actin expression for normalizing the data. The validation experiment indicated equal efficiency of the target amplification and the reference amplification (slope $=0.07$ ). For each strain, the $\Delta C_{T}$ value was determined by subtracting the average actin $\mathrm{C}_{\mathrm{T}}$ from the average CYP51A1 $\mathrm{C}_{\mathrm{T}}$ value. To calibrate the data, the $\Delta \Delta \mathrm{C}_{\mathrm{T}}$ was calculated for each strain by subtracting the $\Delta C_{T}$ from the $\Delta C_{T}$ from strain Ent50, the strain with the highest $\Delta C_{T}$ value and thus the lowest amount of CYP51A1 mRNA. The relative expression of CYP51A1 (CYP51A1 $1_{\mathrm{REL}}$ ) was calculated according to the formula: $2^{-\Delta \Delta \mathrm{CT}}$ with $\Delta \Delta C_{T}+s$ and $\Delta \Delta C_{T}-s$, where $s=$ the standard deviation of the $\Delta \Delta \mathrm{C}_{\mathrm{T}}$ value.

All experiments were performed in a sequence detector using SYBR Green chemistry (SYBR Green RT-PCR kit, Perkin-Elmer Applied Biosystems). The assay targeted a 67-bp region of CYP51A1 amplified with primers AJ753 (5'-GAAACTCTTCGCATGCATTCG-3') and AJ754 (5'-TCGACAGGCATAGGCTGTTTG-3') and a 65-bp region of actin amplified with primers AJ755 (5'-CCGATCGTATGCAAAAGGAAA-3') and AJ756 (5'-GGGCAATGATTTTGACCTTCA-3'). Both primer pairs were designed with Primer Express primer design software from Applied Biosystems. The actin and CYP51A1 gene fragments were amplified in the same run but in separate tubes. Reactions $(30 \mu \mathrm{l})$ were performed containing $1 \times$ SYBR PCR buffer, $5 \mathrm{mM} \mathrm{MgCl} 2,0.3 \mathrm{mM}$ each dATP, dGTP, dCTP, $0.6 \mathrm{mM}$ dUTP, $0.3 \mathrm{mM}$ of each primer, AmpliTaq Gold DNA polymerase $(0.025$ units/ $\mu \mathrm{l})$, and $0.7 \mu \mathrm{l}$ of $1: 5$ diluted cDNA. Both actin and CYP51A1 cDNA were amplified in triplicate reactions following thermocycling program: one cycle of polymerase activation and template denaturation at $95^{\circ} \mathrm{C}$ for $10 \mathrm{~min}$ and 40 cycles at $95^{\circ} \mathrm{C}$ for $15 \mathrm{~s}$ and primer annealing and extension at $58^{\circ} \mathrm{C}$ for $1 \mathrm{~min}$.

Nucleotide sequence accession numbers. The CYP51Al sequence data for V. inaequalis strains Ent27, Ent54, and F445 were deposited in GenBank, Accession Nos. AF227920, AF262756, and AF262757, respectively. The CYP51A1 upstream sequences for strains Ent23, Ent2, Ent7, and UZ4 were deposited under Accession Nos. AF227916, AF227917, AF227918, and AF227919, respectively. The partial actin sequence was deposited under Accession No. AF269254.

\section{RESULTS}

Identification and characterization of CYP51A1. Alignment of the Uncinula necator, Penicillium italicum, and Ustilago maydis CYP51A1 sequences (Accession Nos. U83840, Z49750, and Z48164, respectively) revealed several areas of high homology. Degenerate oligonucleotide primers for amplification of CYP51A1 fragments were designed based on amino acid sequences in four

TABLE 2. Predicted promoters upstream from the CYP51A1 gene from Venturia inaequalis and their location relative to the genes $5^{\prime}$ terminal nucleotide. Shown are 51 bases spanning from -40 to +10 , where +1 is the predicted transcription start site region ${ }^{\mathrm{a}}$

\begin{tabular}{|c|c|c|c|}
\hline Strain & Promoter sequence & Score & Relative location \\
\hline \multicolumn{4}{|l|}{ Ent23 } \\
\hline & CTTGGAGTTAAAATACAGACGAGCAACACCACACTTCCTCACCACCAACA & 0.59 & -50 \\
\hline & +10 & & \\
\hline & $\begin{array}{l}\text { CTTGGAGTTAAAATACAGACGAGCAACACCACACTTCCTCACCACCAACA } \\
\text { ATCGTAACCATAATAAAGGCGTAGGATTGGAAGTTTAATAAGTGGAATCT }\end{array}$ & $\begin{array}{l}0.59 \\
0.93\end{array}$ & $\begin{array}{l}-50 \\
-440 *\end{array}$ \\
\hline & $-40 \quad+1 \quad+10$ & & \\
\hline \multicolumn{4}{|l|}{ UZ4 } \\
\hline & AGGCCCGATTGATATATTACGCCGAGACGGCAATTCCCGTGGCAACCCGC & 0.96 & $-538 *$ \\
\hline & $+1+10$ & & \\
\hline \multicolumn{4}{|l|}{ Ent2 } \\
\hline & CTTGGAGTTAAAATACAGACGAGCAACACCACACTTCCTCACCACCAACA & 0.59 & -50 \\
\hline & TTGGGTTAGTGTAATAAGAAAGTGGGTCAATGGCGGAGCCATTGATTAAG & 0.64 & $-220 *$ \\
\hline & CCCCCGCGGCCCCATTAAAATCATCGTTTCACCCAATCACAGTCACGGAA & 0.76 & $-346 *$ \\
\hline & TCATACTACCCTGTACAAACTCCTACACCCCCGCGGCCCCATTAAAATCA & 0.59 & $-373 *$ \\
\hline
\end{tabular}

a The cutoff value for the determination of scores was 0.5 . The score indicates the likelihood of the nucleotide sequence being a promoter sequence. An asterisk indicates that the promoter is located within an insertion sequence. 
conserved regions. A 350-bp fragment was amplified and sequenced with degenerate primers AJ235 and AJ236. Based on the sequence data, specific primer AJ240 was designed and combined with degenerate primer AJ241 to PCR amplify and sequence a 420-bp region of the gene. Specific primer AJ291 and degenerate primer AJ313 were used to amplify a 900-bp downstream flanking sequence (Fig. 1). Adaptor-ligation PCR with gene-specific and adaptor-specific primers allowed amplification of a 4-kb fragment containing the $5^{\prime}$ end of $C Y P 51 A 1$ and a $3.5-\mathrm{kb}$ fragment containing the $3^{\prime}$ end of CYP51Al from the SacI and DraI PCR libraries, respectively. The CYP51Al gene including introns was 1,674 bp in length and was predicted to have two introns of 50 and $49 \mathrm{bp}$ located after nucleotides 236 and 485, respectively (Figs. 1 and 2). The predicted 5' GT and 3' AG splice sites of the introns were in agreement with typical fungal introns (36). The nucleotide sequence of CYP51A1 was 48.6, 50.6, 52.0, and 40.8\%, and the amino acid sequence was $61.6,63.6,59.8$, and $51.3 \%$ identical to the CYP51Al genes from Uncinula necator, E. graminis, Penicillium italicum, and Ustilago maydis, respectively (GenBank Accession Nos. U83840, AF052515, Z49750, and Z48164, respectively).

Screening for a mutation at codon 133 in CYP51A1. Amino acid sequence alignment of CYP51A1 from Uncinula necator and $V$. inaequalis revealed that codon 136 for tyrosine in Uncinula necator corresponded to codon 133 in V. inaequalis (Fig. 2). A 404-bp fragment containing codon 133 was PCR amplified from each strain with primers AJ243 and AJ244 and used as a template for allele-specific amplification (Fig. 1). DNA from $19 \mathrm{~S}$ and $32 \mathrm{R}$ strains of $V$. inaequalis from Michigan, Israel, France, and Germany was examined by ASA-PCR for a single base pair change at codon 133. After 20 cycles, each isolate yielded the expected 150-bp fragment with primers AJ250 and AJ244. None yielded a product with primer pair AJ251 and AJ244 (Fig. 3, Table 1).

Polymorphism upstream from the $5^{\prime}$ end of CYP51A1. PCR amplification with primers AJ455 and AJ414, using total DNA of 14 single-spore strains, yielded fragments of either 725, 949, 1,225 , or 1,278 bp (Fig. 4). Sequence analysis revealed that the three larger PCR products contained insertions of 225, 500, and $553 \mathrm{bp}$ for strains Ent7, UZ4, and Ent2, respectively (Fig. 1). The 225- and 500-bp insertions were located between nucleotides -319 and -320 , and the 553-bp insertion was located between nucleotides -64 and -65 relative to the first $5^{\prime}$ adenine (A) of the CYP51A1 gene from strain Ent23. All alleles had a common predicted promoter sequence located at nucleotide -50 , and 1,2 , or 3 predicted promoter sequences in the 225-, 500-, and 553-bp insertions, respectively (Table 2 ). $\mathrm{S}$ and $\mathrm{R}$ strains from five orchards in Michigan were screened for the 553-bp insertion using PCR with primers AJ468 and AJ414. The insertion was present in 9 of $11 \mathrm{R}$ strains from the Botany Farm and in one $\mathrm{R}$ strain each from the Entomology Farm and orchard HM; none of the S strains contained the insertion (Table 3). The 225-bp and the 500-bp insertions were found in both $\mathrm{R}$ and $\mathrm{S}$ strains from East Lansing (data not shown).

Sensitivity to myclobutanil and CYP51A1 gene expression in V. inaequalis strains from Michigan orchards. A total of 50, 47, 41, 37, and 48 isolates from the Entomology Farm, Botany Farm, and commercial orchards JM, HM, and ER, respectively, were tested for myclobutanil sensitivity (Fig. 5). The RG value for most isolates from the Entomology Farm were at the sensitive end of the distribution; however, a few $\mathrm{R}$ strains were also detected in this population. The RG values for the isolates in the Botany Farm research orchard and each of the three commercial orchards were clearly shifted to the resistance end of the distribution. The discriminatory dose of myclobutanil use in this study had little or no effect on the $\mathrm{RG}$ of the isolates from these orchards.

For normalizing the CYP51A1 expression data, the actin gene from $V$. inaequalis was identified and partially sequenced. Degenerate primers were designed based on the actin sequences
TABLE 3. Relative expression of the CYP51A1 gene, myclobutanil sensitivity, and presence or absence of the 553-bp insertion in myclobutanil sensitive (S) and resistant (R) strains of Venturia inaequalis from five orchards

\begin{tabular}{|c|c|c|c|}
\hline Population strain ${ }^{\mathrm{a}}$ & Sensitivity ${ }^{\mathrm{b}}$ & 553-bp insertion ${ }^{\mathrm{c}}$ & CYP51A $1_{\text {REL }}{ }^{d}$ \\
\hline \multicolumn{4}{|l|}{ Entomology Farm } \\
\hline Ent2 & $\mathrm{R}$ & + & $5.0(4.2-5.8)$ \\
\hline Ent4 & S & - & $1.8(1.1-2.6)$ \\
\hline Ent7 & $\mathrm{S}$ & - & $3.5(2.7-4.3)$ \\
\hline Ent23 & $\mathrm{S}$ & - & $2.5(1.6-3.4)$ \\
\hline Ent24 & $\mathrm{S}$ & - & $2.6(1.6-3.5)$ \\
\hline Ent27 & $\mathrm{S}$ & - & $1.3(0.6-2.0)$ \\
\hline Ent28 & $\mathrm{S}$ & - & $2.4(1.8-3.1)$ \\
\hline Ent31 & $\mathrm{S}$ & - & $1.8(0.9-2.7)$ \\
\hline Ent50 & $\mathrm{S}$ & - & $1.00(0.3-1.7)$ \\
\hline Ent52 & $\mathrm{S}$ & - & $2.2(1.6-2.9)$ \\
\hline \multicolumn{4}{|l|}{ Botany Farm } \\
\hline $\mathrm{BF} 1$ & $\mathrm{R}$ & + & $5.1(4.1-6.0)$ \\
\hline BF5 & $\mathrm{R}$ & + & $12.9(12.0-13.8)$ \\
\hline BF6 & $\mathrm{R}$ & + & $12.4(11.5-13.2)$ \\
\hline BF8 & $\mathrm{R}$ & + & $4.5(3.6-5.4)$ \\
\hline BF17 & $\mathrm{R}$ & + & $17.8(17.0-18.6)$ \\
\hline BF18 & $\mathrm{R}$ & + & $8.7(7.9-9.5)$ \\
\hline BF19 & $\mathrm{R}$ & + & $7.9(7.0-8.9)$ \\
\hline BF20 & $\mathrm{R}$ & - & $2.9(2.1-3.7)$ \\
\hline BF26 & $\mathrm{R}$ & + & $8.4(7.5-9.2)$ \\
\hline BF29 & $\mathrm{R}$ & - & $3.3(2.4-4.2)$ \\
\hline BF35 & $\mathrm{R}$ & + & $8.0(7.1-8.9)$ \\
\hline \multicolumn{4}{|l|}{ ER-orchard } \\
\hline ER4 & $\mathrm{R}$ & - & $190.4(189.7-191.2)$ \\
\hline ER7 & $\mathrm{R}$ & - & $72.5(71.6-73.4)$ \\
\hline ER8 & $\mathrm{R}$ & - & $76.6(75.8-77.4)$ \\
\hline ER13 & $\mathrm{R}$ & - & $17.6(16.7-18.4)$ \\
\hline ER20 & $\mathrm{R}$ & - & $21.9(21.1-22.8)$ \\
\hline ER22 & $\mathrm{R}$ & - & $20.7(19.8-21.5)$ \\
\hline ER26 & $\mathrm{R}$ & - & $73.3(72.4-74.2)$ \\
\hline ER32 & $\mathrm{R}$ & - & $32.0(31.2-32.8)$ \\
\hline \multicolumn{4}{|l|}{ JM-orchard } \\
\hline JM2 & $\mathrm{R}$ & - & $1.4(0.5-2.3)$ \\
\hline JM8 & $\mathrm{R}$ & - & $2.2(1.3-3.2)$ \\
\hline JM10 & $\mathrm{R}$ & - & $18.9(18.1-19.8)$ \\
\hline JM12 & $\mathrm{R}$ & - & $1.5(0.7-2.3)$ \\
\hline JM13 & $\mathrm{R}$ & - & $1.4(0.4-2.3)$ \\
\hline JM19 & $\mathrm{R}$ & - & $13.9(13.0-14.8)$ \\
\hline JM21 & $\mathrm{R}$ & - & $4.7(3.8-5.7)$ \\
\hline JM23 & $\mathrm{R}$ & - & $4.4(3.5-5.2)$ \\
\hline JM31 & $\mathrm{R}$ & - & $4.3(3.5-5.2)$ \\
\hline \multicolumn{4}{|l|}{ HM-orchard } \\
\hline HM3 & $\mathrm{R}$ & - & $45.3(44.4-46.1)$ \\
\hline HM12 & $\mathrm{R}$ & - & $20.1(19.4-20.9)$ \\
\hline HM13 & $\mathrm{R}$ & - & $19.5(19.0-20.0)$ \\
\hline HM18 & $\mathrm{R}$ & - & $86.2(85.3-87.1)$ \\
\hline HM24 & $\mathrm{R}$ & - & $83.3(82.5-84.1)$ \\
\hline HM25 & $\mathrm{R}$ & + & $5.4(4.5-6.2)$ \\
\hline HM26 & $\mathrm{R}$ & - & $25.5(24.5-26.4)$ \\
\hline HM31 & $\mathrm{R}$ & - & $6.0(5.2-6.8)$ \\
\hline HM35 & $\mathrm{R}$ & - & $22.0(21.0-22.8)$ \\
\hline
\end{tabular}

${ }^{a}$ All strains were isolated from individual lesions. The Botany Farm and Entomology Farm were experimental farms, only $0.1 \mathrm{~km}$ apart. Orchards ER, JM, and HM were commercial orchards located in Michigan.

${ }^{b}$ The reaction of each strain to myclobutanil was determined in mycelial growth assays on potato dextrose agar amended with myclobutanil at 0 and $0.3 \mu \mathrm{g} / \mathrm{ml}$ as described previously (31). A strain was classified as sensitive (S) to myclobutanil if its relative mycelium growth was inhibited by more than $70 \%$ or resistant $(\mathrm{R})$ to myclobutanil if its growth was inhibited by less than $30 \%$ (Fig. 5).

${ }^{c}$ The presence $(+)$ or absence (-) of the 553-bp insert was determined by polymerase chain reaction amplification by primers AJ468 and AJ414.

${ }^{\mathrm{d}} \mathrm{CYP} 51 \mathrm{~A} 1_{\mathrm{REL}}$ is the relative amount of CYP51A1 mRNA as compared with the mRNA level from strain Ent50. This strain was chosen for comparison because it had the lowest amount of mRNA from all samples tested. The amount of target, normalized to an endogenous reference, and relative to a calibrator, is given by $2^{-\triangle \Delta C T}$. The range given of CYP51 $\mathrm{A} 1_{\mathrm{REL}}$ relative to Ent50 is determined by evaluating the expression $2^{-\Delta \Delta C T}$ with $\Delta \Delta C_{T}+s$ and $\Delta \Delta C_{T}-s$, where $s=$ the standard deviation of the $\Delta \Delta C_{T}$ value. 

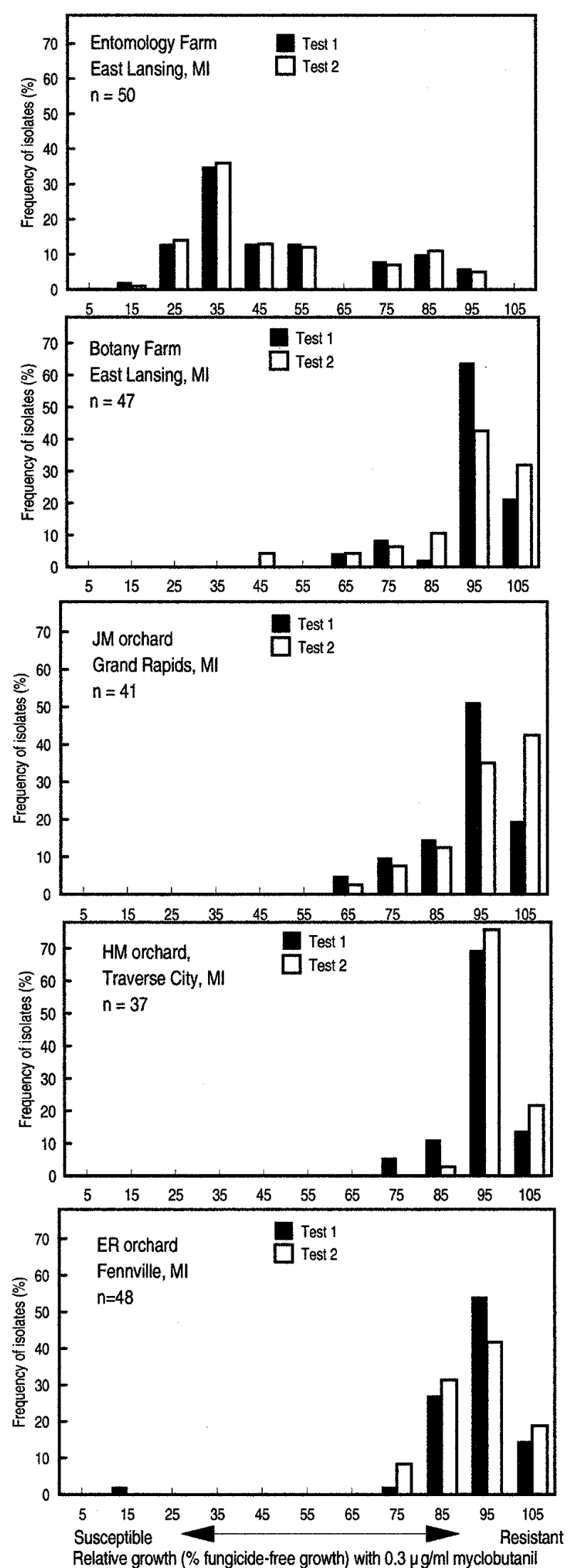

Fig. 5. Frequency distribution based on relative growth on myclobutanilamended medium $(0.3 \mu \mathrm{g} / \mathrm{ml})$ of individual isolates of Venturia inaequalis from a baseline orchard (Entomology Farm), a research orchard for testing demethylation-inhibitor fungicides (Botany Farm), and three commercial Michigan apple orchards with poor control of scab. Relative growth equals the colony diameter on amended medium per colony diameter on unamended medium $\times 100$ from Homo sapiens, Neurospora crassa, and Phytophthora infestans (GenBank Accession Nos. NM001614, U78026, and M59715). Sequence analysis of a 451-bp actin fragment revealed highest nucleotide similarities $(85 \%)$ to the actin genes of $N$. crassa, Colletotrichum gloeosporidoides (GenBank Accession No. AF112537), and Ajellomyces capsulatus (GenBank Accession No. U17498).

Expression of the CYP51Al gene was determined for nine $\mathrm{S}$ strains with RG values less than 30 from an orchard that had never been sprayed with DMI fungicides (baseline orchard Entomology Farm), and $37 \mathrm{R}$ strains with RG values of 95 or higher collected from a research orchard (Botany Farm) and from three commercial Michigan apple orchards (ER, JM, and HM) with a long history of DMI use and a high frequency of R strains (Table 3, Fig. 5). Strain Ent50 was chosen to calibrate all data because among the strains tested it contained the least amount of CYP51A1

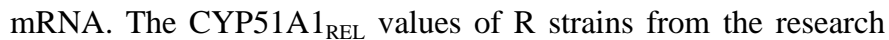
orchard were significantly different from the values obtained from the baseline orchard ( $P<0.05$ according to LSD). Nine of eleven $\mathrm{R}$ strains had higher CYP51A $1_{\mathrm{REL}}$ values than any of the $\mathrm{S}$ strains. The CYP51A $1_{\text {REL }}$ values from $R$ strains from the commercial orchards HM and ER were signifiantly different from the values obtained from the baseline orchard $(P<0.05$ according to the Tukey test). Overexpression of the CYP51Al gene was detected in eight of eight, five of nine, and nine of nine $\mathrm{R}$ strains from orchards ER, JM, and HM, respectively. The addition of $0.3 \mu \mathrm{g} / \mathrm{ml}$ of myclobutanil to the PDB culture medium $24 \mathrm{~h}$ before RNA was extracted from the mycelium did not increase the level of CYP51A1 expression (data not shown).

\section{DISCUSSION}

The putative amino acid sequence of the gene identified in this study closely resembles the cytochrome P450 sterol gene identified in other fungal species. It contains six regions known to be conserved and characteristic for CYP51Als in mammals, yeast, and fungi (2). The sequence also contains two introns that are located exactly at the same position as the introns in Uncinula necator (10). This data strongly suggests that we identified the gene encoding cytochrome P450 sterol $14 \alpha$-demethylase in $V$. inaequalis.

The gene encodes the target enzyme for DMI fungicides, thus resistance could develop from changes in the structure of the CYP51A1 gene thereby reducing the affinity of the target enzyme to these antifungal agents. Several single-site mutations within this gene were linked to DMI resistance in yeast. Most of the mutations found in fluconazole-resistant strains of the yeast fungus Candida albicans were located in the substrate recognition site; they reduced the affinity of the target enzyme for DMI fungicides $(3,29)$. In filamentous fungi such as Uncinula necator, Penicillium italicum, and E. graminis, a single nucleotide mutation within the substrate recognition site, causing an amino acid change from phenylalanine to tyrosine, has been correlated with resistance $(6,9,11)$. No mutations in the CYP51Al gene from $V$. inaequalis were found when two $\mathrm{R}$ and one $\mathrm{S}$ strains were completely sequenced. In addition, the point mutation reported to correlate with DMI resistance in filamentous fungi was not detected in a collection of strains from Michigan, Germany, Israel, and France. These results indicate that a resistance mechanism other than mutation of the CYP51A1 gene is primarily the cause of DMI resistance in $V$. inaequalis strains from Michigan and elsewhere.

Increased expression of CYP51A1 is another mechanism of DMI resistance. Recently, it was shown that overexpression of the Saccharomyces cerevisiae CYP51A1 gene, under control of the regulatable promoter $G A L 1$, can result in azole resistance (22). In fluconazole-resistant clinical isolates of $C$. albicans, resistance was associated with less than a fivefold increase in the level of CYP51A1 mRNA $(1,30,42)$. Heterologous expression of the Peni- 
cillium italicum CYP51A1 gene in Aspergillus niger revealed a twofold to fivefold increase of DMI resistance $(39,40)$. The CYP51A $1_{\text {REL }}$ values for $R$ strains from the Botany Farm research orchard and commercial orchards ER and HM were significantly higher than the values for $\mathrm{S}$ strains from the baseline Entomology orchard. Many CYP51A $1_{\text {REL }}$ values exceeded dramatically the less than fivefold increase in expression found in fluconazoleresistant $C$. albicans isolates $(1,30,42)$. Heterologous expression of the $V$. inaequalis CYP51A1 gene from strain Ent2 in a PDR5::Tn5 $S$. cerevisiae strain revealed a fivefold increase of myclobutanil resistance (data not shown). These findings provide strong evidence that overexpression of the CYP51Al gene is associated with DMI resistance in field strains of $V$. inaequalis collected from research and commercial orchards with practical resistance to DMI fungicides.

Overexpression of CYP51A1 in resistant strains theoretically could be a result of gene amplification, up-regulation of transcription, or a higher degree of mRNA stability all resulting in elevated CYP51A1 mRNA levels. Sequence analysis of the CYP51A1 5' flanking sequence revealed the presence of three insertions within 320 bp of the CYP51A1 5' end. Interestingly, the 553-bp insertion, which contained three predicted promoter sequences, was found in every $\mathrm{R}$ strain from the Botany Farm with CYP51A $1_{\text {REL }}$ values $>4.5$, but not in $\mathrm{R}$ strains with lower levels of CYP51A1 expression nor in $\mathrm{S}$ strains. Promoters located upstream or downstream from a gene often regulate gene expression by stimulating or inhibiting the initiation of transcription. The presence of a 126-bp repeat unit in the promoter region is responsible for CYP51A1 overexpression in DMI resistant Penicillium digitatum strains (15). Insertions located upstream and downstream of a gene promoter generate different patterns of gene expression (5). Therefore, the 553-bp insertion or its promoters may serve as a transcriptional enhancer of CYP51A1 expression, resulting in DMI resistance. Unfortunately, no $\mathrm{S}$ strains were detected among the isolates collected from the myclobutanil-sprayed trees in the Botany Farm orchard. Instead, we examined the $S$ strains from the nearby Entomology Farm orchard, because short distance gene flow likely exists between adjacent $V$. inaequalis populations (34). Gene flow between the two orchards is supported by detection of a few R strains among a high frequency of $S$ strains in the Entomology Farm orchard. Therefore, it is likely the $\mathrm{R}$ strains migrated into this orchard from the Botany Farm, the only other apple orchard in the surrounding area. However, other insertions or mechanisms seem to be responsible for the dramatic overexpression of CYP51A1 in many of the $\mathrm{R}$ strains from commercial orchards.

DMI-resistant field strains of $V$. inaequalis can be controlled to a certain degree by increased DMI fungicide application rates (20). However, even at higher rates the level of control may be commercially unacceptable, in particular where curative control is needed (21). The enhanced concentration of CYP51A1 mRNA in many R strains most likely results in higher levels of $14 \alpha$-demethylase in fungal cells. Elevated enzyme production may explain why increasing rates of DMI fungicides have been required to maintain control. The detection of $\mathrm{R}$ strains in the experimental and one commercial orchard without increased levels of enzyme production indicates that other mechanisms might also contribute to myclobutanil resistance in $V$. inaequalis. Recently, Palani and Lalithakumari (27) provided evidence that penconazole-resistant laboratory mutants of $V$. inaequalis possess an energy-dependent efflux mechanism. It remains to be investigated whether $\mathrm{R}$ strains without increased $14 \alpha$-demethylase production have increased levels of drug efflux activity. However, regardless of the mechanism for resistance at each orchard site, the detection of $\mathrm{R}$ strains at high frequency in a commercial orchard in 1995 (21) and in three additional commercial orchards in 1999 (this study), indicates that apple scab is becoming increasingly hard to control with DMI fungicides.

\section{ACKNOWLEDGMENTS}

This research was supported, in part, by the Michigan Agricultural Experiment Station. We thank E. L. Schnabel for technical advice and helpful discussions, and K. Kása, G. Ehret, and D. Almy for technical assistance.

\section{LITERATURE CITED}

1. Albertson, G. D., Niimi, M., Cannon, R. D., and Jenkinson, H. 1996. Multiple efflux mechanisms are involved in Candida albicans fluconazole resistance. Antimicrob. Agents Chemother. 40:2835-2841.

2. Aoyama, Y., Noshiro, M., Gotoh, O., Imaoka, S., Funae, Y., Kursoawa, N., Horiuchi, T., and Yoshida, Y. 1996. Sterol 14-demethylase P450 (P45014DM) is one of the most ancient and conserved $\mathrm{P} 450$ species. J. Biochem. 119:926-933.

3. Asai, K., Tsuchimori, N., Okonogi, K., Perfect, J. R., Gotoh, O., and Yoshida, Y. 1999. Formation of azole-resistant Candida albicans by mutation of sterol 14-demethylase P450. Antimicrob. Agents Chemother. 43:1163-1169.

4. Braun, P. G., and McRae, K. B. 1992. Composition of a population of Venturia inaequalis resistant to myclobutanil. Can. J. Plant Pathol. $14: 215-220$.

5. Chisholm, G. E., and Cooper, T. G. 1992. Ty insertions upstream and downstream of native DUR1,2 promoter elements generate different patterns of DUR1,2 expression in Saccharomyces cerevisiae. J. Bacteriol. 174:2548-2559.

6. de Waard, M. A. 1996. Molecular genetics of resistance in fungi to azole fungicides. ACS Symp. Ser. 645:62-71.

7. de Waard, M. A. 1993. Recent developments in fungicides: Modern Crop Protection and Perspectives. J. C. Zadoks, ed. Wageningen Pers, Wageningen, Netherlands.

8. Del Sorbo, G., Andrade, A. C., van Nistelrooy, J. G. M., van Kan, J. A. L., Balzi, E., and de Waard, M. A. 1997. Multidrug resistance in Aspergillus nidulans involves novel ATP-binding cassette transporters. Mol. Gen. Genet. 254:417-426.

9. Delye, C., Bousset, L., and Corio-Costet, M. F. 1998. PCR cloning and detection of point mutations in the eburicol $14 \alpha$-demethylase (CYP51) gene from Erysiphe graminis f. sp. hordei, a "recalcitrant" fungus. Curr. Genet. 34:399-403.

10. Delye, C., Laigret, F., and Corio-Costet, M.-F. 1997. Cloning and sequence analysis of the eburicol 14-alpha demethylase gene of the obligate biotrophic grape powdery mildew fungus. Gene 195:29-33.

11. Deleye, C., Laigret, F., and Corio Costet, M. F. 1997. A mutation in the $14 \alpha$-demethylase gene of Uncinula necator that correlates with resistance to a sterol biosynthesis inhibitor. Appl. Environ. Microbiol. 63:2966-2970

12. Franz, R., Kelly, S. L., Lamb, D. C., Kelly, D. E., Ruhnke, M., and Morschhaeser, J. 1998. Multiple molecular mechanisms contribute to a stepwise development of fluconazole resistance in clinical Candida albicans strains. Antimicrob. Agents Chemother. 42:3065-3072.

13. Garber, R. C., and Yoder, O. C. 1983. Isolation of DNA from filamentous fungi and separation into nuclear, mitochondrial, ribosomal, and plasmid components. Anal. Biochem. 135:416-422.

14. Golembiewski, R. C., Vargas, J. R., Jones, A. L., and Detweiler, A. R. 1995. Detection of demethylation inhibitor (DMI) resistance in Sclerotinia homeocarpa populations. Plant Dis. 79:491-493.

15. Hamamoto, H., Hasegawa, K., Nakaune, R., Lee, Y. J., Makizumi, Y., Akutsu, K., and Hibi, T. 2000. Tandem repeat of a transcriptional enhancer upstream of the sterol 14 alpha-demethylase gene (CYP51A1) in Penicillium digitatum. Appl. Environ. Microbiol. 66:3421-3426.

16. Hitchcock, C. A. 1993. Resistance of Candida albicans to azole antifungal agents. Biochem. Soc. Trans. 21:1039-1047.

17. Jones, A. L., Shabi, E., and Ehret, G. R. 1987. Genetics of negatively correlated cross-resistance to a N-phenylcarbamate in benomyl-resistant Venturia inaequalis. Can. J. Plant Pathol. 9:195-199.

18. Joseph-Horne, H., and Hollomon, D. W. 1997. Molecular mechanisms of azole resistance in fungi. FEMS Microbiol. Lett. 149:141-149.

19. Joseph-Horne, T., Hollomon, D., Loeffler, R. S., and Kelly, S. L. 1995. Altered P450 activity associated with direct selection for fungal azole resistance. FEBS Lett. 374:174-178.

20. Köller, W., and Wilcox, W. F. 1999. Evaluation of tactics for managing resistance of Venturia inaequalis to sterol demethylation inhibitors. Plant Dis. 83:857-863.

21. Köller, W., Wilcox, W. F., Barnard, J., Jones, A. L., and Braun, P. G. 1997. Detection and quantification of resistance of Venturia inaequalis populations to sterol demethylation inhibitors. Phytopathology 87:184-190.

22. Kontoyiannis, D. P., Sagar, N., and Hirschi, K. D. 1999. Overexpression of Erg11p by the regulatable GAL1 promoter confers fluconazole resis- 
tance in Saccharomyces cerevisiae. Antimicrob. Agents Chemother. 43:2798-2800.

23. Kuck, K. H., and Scheinpflug, H. 1986. Biology of sterol-biosynthesis inhibiting fungicides: Chemistry of Plant Protection. G. Haug and H. Hoffman, eds. Springer-Verlag, Berlin.

24. Kunz, S., Deising, H., and Mendgen, K. 1997. Acquisition of resistance to sterol demethylation inhibitors by populations of Venturia inaequalis. Phytopathology 87:1272-1278.

25. Nakaune, R., Adachi, K., Nawata, O., Tomiyama, M., Akutsu, K., and Hibi, T. 1998. A novel ATP-binding cassette transporter involved in multidrug resistance in the phytopathogenic fungus Penicillium digitatum. Appl. Environ. Microbiol. 64:3983-3988.

26. Nelson, D. R., Koymans, L., Kamataki, T., Stegeman, J. J., Feyereisen, R., Waxman, D. J., Waterman, M. R., Gotoh, O., Coon, M. J., Estabrook, R. W., Gunsalus, I. C., and Nebert, D. W. 1996. P450 superfamily: Update on new sequences, gene mapping, accession numbers, and nomenclature. Pharmacogenetics 6:1-42.

27. Palani, P. V., and Lalithakumari, D. 1999. Resistance of Venturia inaequalis to the sterol biosynthesis-inhibiting fungicide, penconazole [1-(2(2,4-dichlorophenyl)pentyl)-1H-1,2,4-triazole]. Mycol. Res. 9:1157-1164.

28. Reese, M. G., and Eeckman, F. H. 1995. New neural network algorithms for improved eukaryotic promoter site recognition. Genome Sci. Technol. 1:45.

29. Sanglard, D., Ischner, F., Koymans, L., and Bille, J. 1998. Amino acid substitutions in the cytochrome P-450 lanosterol 14-alpha demethylase (CYP51A1) from azole resistant Candida albicans clinical isolates contribute to resistance to azole antifungal agents. Antimicrob. Agents Chemother. 42:241-253.

30. Sanglard, D., Kuchler, K., Ischer, F., Pagani, J. L., Monod, M., and Bille, J. 1995. Mechanisms of resistance to azole antifungal agents in Candida albicans isolates from AIDS patients involve specific multidrug transporters. Antimicrob. Agents Chemother. 39:2378-2386.

31. Schnabel, G., Schnabel, E. L., and Jones, A. L. 1999. Characterization of ribosomal DNA from Venturia inaequalis and its phylogenetic relationship to rDNA from other tree fruit Venturia species. Phytopathology 89:100-108.

32. Siebert, P. D., Chenchik, A., Kellogg, D. E., Lukyanov, K. A., and Lukyanov, S. A. 1995. An improved PCR method for walking in uncloned genomic DNA. Nucleic Acids Res. 23:1087-1088.

33. Stanis, V. F., and Jones, A. L. 1985. Reduced sensitivity to sterol-inhibiting fungicides in field isolates of Venturia inaequalis. Phytopathology
75:1098-1101

34. Tenzer, I., and Gessler, C. 1999. Genetic diversity of Venturia inaequalis across Europe. Eur. J. Plant Pathol. 105:545-552.

35. Thind, T. S., Clerjeau, M., and Olivier, J. M. 1986. First observation on resistance in Venturia inaequalis and Guignardia bidwelli to ergosterolbiosynthesis inhibitors in France. Proc. Br. Crop Prot. Conf. Pests Dis. 2:491-498.

36. Unkles, S. E. 1992. Gene organization in industrial filamentous fungi: Applied Molecular Genetics of Filamentous Fungi. J. R. Kinghorn and G. Turner, eds. Blackie, London.

37. van den Bossche, H., Dromer, F., Improvisi, I., Lozano-Chiu, M., Rex, J. H., and Sanglard, D. 1998. Antifungal drug resistance in pathogenic fungi. Med. Mycol. 36:119-128.

38. van den Bossche, H., Marichal, P., Gorrens, J., Bellens, D., Moereels, H., and Janssen, P. A. J. 1990. Mutation in cytochrome P450-dependent 14alpha demethylase results in decreased affinity for azole antifungals. Biochem. Soc. Trans. 18:56-59.

39. van den Brink, H. J. M., Nistelrooy, H. J. G. M., de Waard, M. A., van den Hondel, C. A. M. J. J., and van Gorcom, R. F. M. 1996. Increased resistance to 14 alpha-demethylase inhibitors (DMIs) in Aspergillus niger by coexpression of the Penicillium italicum eburicol 14 alpha-demethylase (cyp51) and the A. niger cytochrome P450 reductase (cprA) genes. J. Biotechnol. 49:13-18.

40. van Nistelrooy, J. G., van den Brink, J. M., van Kan, J. A., van Gorcom, R. F., and de Waard, M. A. 1996. Isolation and molecular characterization of the gene encoding eburicol 14-alpha demethylase (CYP51) from Penicillium italicum. Mol. Gen. Genet. 250:725-733.

41. Walmsey-Woodward, D. J., Laws, F. A., and Whittington, W. J. 1979. Studies on the tolerance of Erysiphe graminis f. sp. hordei to systemic fungicides. Ann. Plant Biol. 92:199-209.

42. White, T. C. 1997. Increased mRNA levels of Erg16, CDR, and MDRI correlate with the increases in azole resistance in Candida albicans isolates from a patient infected with human immunodeficiency virus. Antimicrob. Agents Chemother. 41:1482-1487.

43. White, T. C. 1997. The presence of an R467K amino acid substitution and loss of allelic variation correlate with an azole-resistant lanosterol 14-alpha demethylase in Candida albicans. Antimicrob. Agents Chemother. 41:1488-1494.

44. White, T., Marr, K., and Bowden, R. 1998. Clinical, cellular and molecular factors that contribute to antifungal drug resistance. Clin. Microbiol. Rev. 11:382-402. 